\title{
XLII. Researches respecting the laws of affinity
}

\section{Berthollet}

To cite this article: C. Berthollet (1801) XLII. Researches respecting the laws of affinity, Philosophical Magazine Series 1, 9:36, 342-352, DOI: 10.1080/14786440108562708

To link to this article: http://dx.doi.org/10.1080/14786440108562708

曲 Published online: 25 Jan 2010.

Submit your article to this journal $\pi$

LII Article views: 4

Q View related articles $₫$ 
The liquor furnithed by the fkins, \&c, when fubjected to the prefs is lefs coloured.

The fouthern wines, and; in general, thofe made from grapes collected in places well expofed to the fouth, are more coloured than the wines of the north.

Such-are the practical axioms which have been fanctioned by long experience. Two fundamental truths thence refult : the firt is, that the colouring principle of wine exifts in the finins of the grapes; the fecond is, that this principle does not detach itfelf, and is not completely diffolved in the vintage but when the alcohol is developed in it.

We fhall treat in the proper place of this colouring prin ciple, and thall thow, that though it approaches refins in fome of its properties, it is, however, effentially different.

Any one, after this mort explanation, may account for all the proceffes ufual for obtaining wines more or lefs coloured; and may readily conceive that it is in the power of the agriculturift to give to his wines whatever tint of colour he choofes.

[To be continued.]

XLII. Refearcbes reppecting the Laws of Affinity. By C. Bertholiet; Member of the Frencb National Inftitute.

[Continued from p. 153.]

X. Of the Determination of Eleqive Affinities.

To determine the elective affinity of two fubftances for a third, according to the idea which we ought to form of it, is to afcertain in what ratio this third fubftance ought to divide its action between the two former, and at what degree of faturation each of them ought to be when their forces are equally oppofed. The refpective affinities will be proportional to the degree of faturation which each has attained in proportion to the quantity which has acted; fo that, if the quantities are equal, the comparative degree of faturation will give the meafure of the refpective affinities.

2d, When I fpeak of the faturation of a fubfance, I do 
not mean the abfolute faturation at which all reciprocal action would ceafe; but a degree of faturation which it is eafy to afcertain, and which is common to all combinations: it is that of neutralifation, when the properties of neither of the conftituent parts predominate. The term of the cryftallifation of falts does not always coincide with neutralifation: for example, in regard to alkaline carbonats, which ftill give figns of alkalinity, and in regard to the acidulous tartrite of potafh, whiclr, on the other hand, retains an excefs of acid. The laft combination, however, may be taken at the term at which it is neutral, becaufe it ftill has the property of cryftallifation : it is even this tartrite that is neceffarily obtained when in the experiment there is prefent an excefs of the bafe; but when there is an excefs of acid, the degree of faturation of the acidulous tartrite of potan may be determined by the quantity of potalh neceffary to neutralife it.

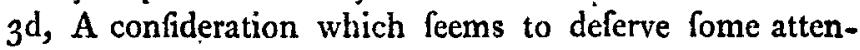
tion is, that in comparing affinities it would be neceffary to employ in all the experiments the fame proportions of all the fubftances fucceffively fubjected to operation; becaufe, if the proportions vary, the refult of the action not being the fame, the affinity could no longer be reprefented by the fame number. I thall render this obfervation more fenfible by an example :

Let 100 reprefent the potah, which ought to be faturated by 100 parts of fulphuric acid, and let 100 parts of foda be oppofed to it. Let us fuppofe that after the action it is found that the patafh has taken up 60 parts of acid, and the foda 40. I hould thence conclude that the affinities of thefe two bafes for the fulphuric acid are in the ratio of 60 to 40 : but there remain 40 parts of potafh uncombined, which really continue to act, and which by their action contribute to divide the acid ; fo that, if this quantity be varied, the refult cannot be the fame; for if, inftead of 100 parts of potarh, and 100 parts of foda, we take 80 parts of each, we thall have for the uncombined portion 20 parts of potath and another quantity of foda ; fo that the forces exercifed by thefe two parts are no longer in the former ratio : hence it refults that the two faturations cannot be in the ratio of 60 to 40. 
4 th, But to afcertain the degree of faturation to which each of thefe fubltances can attain, a feparation muft be made, which can only be effected by the elafticity, cryftallifation, precipitation, or action of a folvent: but we have feen that thefe different means ought to be confidered as foreign forces, which alter the refults, and which determine the combinations formed, without a poffibility of our meafuring their effect fo as to difengage from it that of the elective affinity; fo that the feparations which in articles I, II. III. were confidered only as an effect of elective affinity and of proportions, are really the effect of a concourfe of feveral forces, as is proved by the obfervations which followed thefe articles.

When it is neceflary, for example, to afcertain the quantity of the fulphat of potafh and of foda formed, as the force of cohefion of thefe two fulphats does not much differ, it is probable that it would not occafion much change in the proportions of the two falts which would cryftallife, but it would be neceflary to feparate the excels of the alkali by means of alcohol in order to obtain the whole cryftallifation; but alcohol not acting with equal force upon potarh and foda, would produce a new change. To thefe confiderations we may add, that a change of proportions would not only make the force of the foda and the potah (No. I.) to vary, but alfo that of the alcohol, not to mention the affinity of the water, which ferves as the folvent.

If barytes were to be compared with either potafh or foda, we fhould have changes ftill more confiderable : in that cafe, the force of cohefion of the fulphat of barytes would be fuch that it would leave to the alkali but a very fmall quantity of fulphuric acid, which would be the expreffion of the ratio of the force of the cohefion of the fulphat of barytes to that of the folvent, rather than of the affinity of the barytes to that of the alkali.

This is fo certain, that if, with the view of comparing the affinity of the acids for barytes, we fhould begin by treating the barytes with an excefs of fulphuric acid, it would be almot entirely precipitated, unlefs the acid were highly concentrated; it would even be impolfible to difinguith the combined 
combined portion from that which is not, and to fay that the barytes has more affinity for the former than for the latter. This, however, is what is really faid when it is affirmed that the fulphuric acid has more affinity for the barytes than any other acid has, becaufe a fulphat of barytes is formed by precipitation; and thus an effect, which depends in particular on the force of cohefion peculiar to the fulphat of barytes, is afcribed to elective affinity.

It is manifent, therefore, that the elective affinity of two fubftances in regard to a third, cannot be determined by a direct experiment even when trial is made on two fubltances which are in a liquid, and which may become neutralifed by faturation; fince, in order to afcertain the faturation, it is neceffary to employ the intervention of foreign forces.

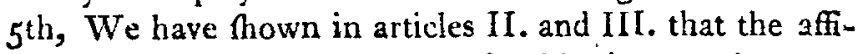
nity of a fubftance may be compenfated by its quantity.

From this confideration it would appear that it is fufficient to afcertain the capacities of faturation of different bafes for an acid, or of different acids for a bafe, in order to eftablith the ratio of their affinity; for it ought to be in the inverfe ratio of the quantities neceffary to produce the fame degree of faturation.

This confequence, however, is erroneous when we are defirous of applying it to the elective affinities ; becaufe, as foon as the two fubftances are put in circumftances to combine with a third, new forces are eftablifhed, which not only determine other refults, but even change the conftitution of thefe fubftances. Thus, if we compare the fulphuric acid with carbonic acid, it is certain, that if a quantity of potah be brought to the term of neutralifation by carbonic acid, it exercifes a force as great as the quantity of fulphuric acid which would be neceffary, to produce the fame effect: and yet if fulphuric acid be poured on the combination thus formed, all the carbonic acid is difengaged; becaufe, not being retained by an equal force, it refumes the elaftic ftate: and even if it be retained by a fufficient quantity of water, it will no longer be in the fame ftate of compreffion; it will no more have the fame conftitution; it will no longer be the fame fubftance in regard to chemical action. In a word, Vol. IX. X x 
ive muft apply to the action of fubftances unequally faturated the obfervations made in the preceding articles.

A comparifon, then, of the capacities of faturation, though it may conduct to important confiderations, cannot be applied to the determination of elective affinities.

\section{Of Jome Errors wbicb arife from a falfe Idea of Elective Affinity:}

Ift, I thall here difcufs foine opimions adopted refpecting elective affinitics:- I fhall fhow how little foundation they have, and fhall oppofe to them the application of principles eftablifhed in the preceding articles.

Beaune obferved that when the fulphat of potath was dif folved, by means of heat, in an equal. weight of nitric acid, cryftals of nitrat of, potath were obtained by cooling. He afcribes this decompofition of the fulphat of potaln to reciprocal affinities, which produce oppofite combinations without determining the caufe of this contrary effect.

2d, The explanation of this remarkable fact has been contradicted by Bergman. He obferves that there are falts which tend to have an excefs of acid, fuch as the acidulous tartrite of potath. He is of opinion that, when thefe falts are in a ftate of neutralifation, we muft confredr their bafe as divided into two parts; one upon which the whole action of the acid is particularly exercifed to form an aeidulous falt, while the other part only tends to fatisfy the excefs of acidity in the acidulous falt. This part of the bale is retained then only by a weak acidity, and it may be taken away by an acid very inferior to that which enters into the firft combination. Thus the acetous acid may take away part of the potafh, which in the tartrite of potafh is fuperfluous, to the combination that conftitutes the acidulous tartrite of potafh, thotigh this acid has a moth weaker affinity than the tartareous acid.

But the fulphat of potafi is among the number of thofe falts which tend to form an acidulous falt; nearly wo-thirds of it bafe enter into this combination, and it is only this portion which is fubject to all the affinity of the folpturic cid; the other third may be feparated by an acid of an afinity inferior to that of the fulphwric acid, fuch as the rnitrias, 
muriatic, or tartareous acid. When the decompofition is earried to its boundary, it ftops, whatever may be the quantity of the acid oppofed; and if the quantity is not too great to prevent cryftallifation, or if the excefs be expelled by heat, an acidulous fulphat, which forms cryftals permanent in the air, will be obtained by folution and evaporation.

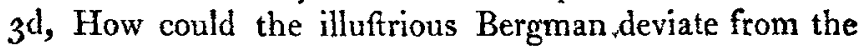
route traced out to him by obfervation? His own experiments, even, prove that the acid, which is fuperabundant in the acidulous fulphat of potalh, exercifes its affinity; that it is in combination; and that it acts in the ratio of its quantity : for he fays, that if fulphuric acid be added to the acidulous fulphat of potah, this falt diffolves, and lofes its property of cryftallifing; that this excefs of acid can with difficulty be expelled even by diftillation in a retort; and that, to produce this effect, the faline combination muft be fufed in a crucible, or be expofed feveral times to the action of very pure alcohol.

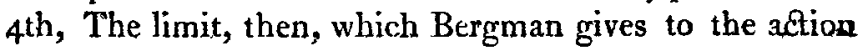
of acids on the acidulous fulphat is ideal. This fulphat exhibits the fame phænomena as all the falts which are capable of refifting, to a certain degree, the action of an excefs of acid or bafe (Art. V. No. 4.), as well as the action of another acid or a foreign bafe. The only difference there is between them in this refpect depends on the force of cohefion which may act more or lefs to produce cryftallifation, and which is proper to certain proportions of acid and bafe; probably a confequence of the figure affumed by the moleculæ of their combination.

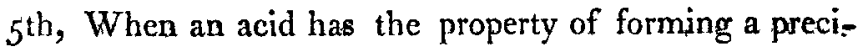
pitate by combining with a bafe, it is concluded that it has more affinity for that bafe than for the acid with which it was firft united, without examining how far the new acid may have operated the decompofition, and without reflecting that an oppofite decompofition takes place by a fimple change of proportions, and might confequently conduct to an oppofite conclufion.

Thus, as the tartareous acid has the property of forming, with potarh, an acidulous falt very little foluble, and confequently forms a precipitate with all falts having a bafe of 
potafh, and not diluted with too large a quantity of water, it has been concluded that it has more affinity for potath than the other acids. Bergman has excepted the fulphuric acid, becaufe he fuppofed that the tartareous acid could act only on the potan redundant to the combination of the acidulous fulphat of potath; a fuppofition which, I think, I have already defroyed in the preceding articles. He has excepted alfo the nitric and muriatic acids, becaufe he fuppofed that the tartareous acid thowed the fame phænomena in regard to the nitrat and muriat of potath as in regard to the fulphat; though he has not afcertained the exiftence of an acidulous nitrat and muriat of potaith analogous to the acidulous fulphat of potath.

He alfo concludes, from experiments made on falts having a bafe of foda, but without making the experiments known, that the tartareous acid ought to be placed after the oxalie acid: but, not to dwell on thefe exceptions, the tartareous acid, according to him, decompofes completely all the other falts with a bafe of fixed alkali.

What embarraffes Bergman is, that the tartareous acid produces no precipitate with falts that have a bafe of foda. In his opinion, this apparent difference depends on the foda not having the property of forming a falt but litile foluble, by taking up an excefs of acid; but in that cafe there is no eviderice of a decompofition, and we are to be fatisfied with the probability that the affinities of the one fixed alkali follow the fame order as thole of the other.

All this claffification of affinities is founded on the falfe fuppofition, that one acid expels another from its combinations by its affinity alone confidered as a conftant force; and this fuppofition renders others neceflaty in order to explain, as exceptions, thofe facts neceffarily arifing from a general property.

6th, I have examined the decompofition of acidulous tartrite of potafh by the nitric acid, which, according to the received ideas, which I then adopted, ought to decompofe it by feizing entirely on its bafe. I digefted acidulous tartrite of potalh and nitric acid, and obtained, by cooling, beautiful cryftals of nitrat of potahh. I repeated the aperation feveral 
times, adding nitric acid until no more nitrat of potalh was feparated. I then expofed the liquor to a heat fufficient to caufe the nitric acid which might be free, to evaporate without altering the tartareous acid. After this the liquor had an oily confiftence; it was defitute of fnell, and announced neither the exiftence of nitric acid nor that of potafh; but when expofed to a ftrong heat there was difengaged a great deal of nitrous gas, the tartareous acid was reduced to charcoal, and its afhes gave a confiderable quantity of carbonat of potath.

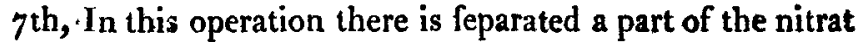
of potafh, effected by the cryftallifing force of that falt, and carried by it juft to the degree when that force is exceeded. by the fuperabundant acid. The acidulous tartar is rendered foluble by the action of the nitric acid, which takes from it at the fame time, by cryftallifation, a part of the bafe neceffary for its infolubility.

On the other hand, tartareous acid added to a folution of nitrat of potafh, takes up, to a certain term, the potah from the nitric acid, and forms an acidulous tartrite, which is precipitated; but, as it has not the property of forming an acidulous tartrite of foda little foluble, it does not produce a precipitate with falts having a bafe of foda.

In both thefe cafes, every thing that cannot be feparated by the force of cohefion forms a liquid, in which the fubftances exercife an action proportioned to their prefent maffes.

Nothing, then, can be concluded in regard to the refpective affinity from thefe feparations, which are effected by precipitation or cryftallifation; - fince, by the change of the proportions alone, oppofite decompofitions may be often obtained.

8th, The precipitation obferved to take place, when, in comparing the affinities of two bafes, one of them was found to have formed an infoluble combination, gave rif to an error of the fame kind; and it is on this foundation alone that it has been afferted that lime has more affinity than alkali for the fuoric; phofphoric, and arfenic acids: in a word, for all thofe which form with it an infoluble combination; and, confequently, that it has the property of decompofing entirely the falts formed by an alkali and thefe acids. 
This precipitation is not the refult of elective affinity, and it is not complate, but its quantity is determined by the ratiu of the astion of the liquid to the eohefive force of the precipitate : hence it happens that the precipitate is often re-diffolved on nugmenting the grantity of the fubftance oppofed to it.

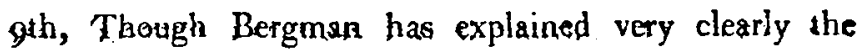
changes which hent may produce on chemical action when the fubstances have a difpofition to volatilifation; and though he even reconmends to avoid too Arong heat in evaporation, the extent of the inffuence which it may have in the operations by which falts are feparated, in order to form a judgasent of their affinities, has not yet been fully difouyered.

It ought not to have been concluded that the fulphuric acid has more affinity for frxad alkalies than the nitric or muriatic acids, merely becaure that by a ftrong beat it expels thefe acids from their combinations. Chemilts flould have obferved that, even by the heat employed to produce evaporation, and to caufe falts to cryftallife, the proportions of the volatile acids may be confiderably changed in regard to the fulphuric acid which remains oppofed to them, and that the latter may at length entirely expel them, by means of the difference which exilts between its fixity and that of thefe acids. (Art. VII. No. 5.)

zoth, We are indebted to Bergman for ufeful obfervations on the errors which may arife from the folubility of one fubftance, which is elininated, and of which the feparation is wot obferved. He remarks that potaih and foda do not difturb the tranfparency of the folution of a falt with a bafe of lime, if this folution be diluted with fifty times as much water, becaufe the lime feparated, bcing foluble, remains in the water; but he did not reflect that, if the lime, in that cafe, had no more than its natural folubility, it would be a very weak obftacle to its preoipitation, for it requires nearly feven hundred parts of water to diffolve it: what adds greatly to its natural folubility is, that it continues to be in combination with the acid (Art. V. No. 5.), and that it cannot be feparated but by retaining a part (Art. III. No. 9.), which increafes iss folubility. 
Irth, Notwithftanding his general obfervations, Bergmari inifook the effects of folubility in feveral cafes : thus, he did not think that the nitric and muriatic acids had an action on the combination of the phofphat of lime, thotugh the only difference that can be eftablinhed in this refpect between thele two acids and the fulphuric acid, the comparative force of their affinities not being known, is, that the two former form only foluble combinations, while that produced by the fulphuric acid may be withdrawn, in a great meafure, by the force of cryftallifation.

I2th, It is the folubility of the lime as well as of the barytes, increafed by the action of the acid on thefe earths, which caufes ammonia not to produce any precipitate in the folution of the falts of which they are the bafe. The firft portion of the ammonia, however, nifixed; for example, with the muriat of lime, fearcely fuffers any odour to be exhaled; which indicates that it has entered into combination, and that its action may be rendered fenfible, as thall be trere thown.

I mixed ammonia with a folution of the murriat of lime, and I caufed the liquor to evaporate in a retott: when it was reduced to a certain point, there was furmed a pretty confiderable precipikate. I continued the operation, at the end of which the quantity of the precipitate was very much diminifhed; there was formed a pelficle; and, by cooling, a large quantity of cryftals in pretty long needles. It was a triple falt; from which the ammonia could be diffengaged by lime. This falt, when rediffolved, and evaporated in the open air, gave no more indications of ammonia in the proof by lime.

It is feen, then, that, when the water has not been too abundant, the ammonia precipitated part of the frme, though it was rendered much more foluble by the acid; and though the action of the ammonia was confiderably. weakened. by the heat, which diminifhed its affinity and its quantity. In proportion as the latter was reduced, the precipitate was re-diffolved: there however ftill remained ammonia after a long evaporation, and it was only by the help of the action of the air that it was entirely diffipated. ${ }^{2}$ The feparation of 


\section{Experiments and. Remarks on Galvanifm.}

the lime would, no doubt, become much more fenfinle if the ammoniacal gas were received in a ftrong folution of the muriat of lime.

If the ammonia produces a precipitate with falts having a bafe of alumine, it is becaufe this earth has lefs folubility than lime, even when it is combined with the portion of the acid which it retains while it is precipitated.

[To be continued.]

XLIII. Experiments and Remarks on Galvanifm. A Letter from a Correfpondent to the Editor.

SIR,

1 AVING read, with much plealure, in your very valuable monthly publication, the feveral opinions and experiments refpecting the influence excited in the pile of Volta, $I$ take the liberty of fubmitting to you fome obfervations on the fame fubject.

It has been faid by fome very ingenious experimentalifts that the oxydation of one fide of the plates, or the difference of oxydation in the two metals, or between one metal and different fluids, is the caufe of the production of the galvanic influence. I find that the acids increafe the power of my pile, and I alfo find, when the papers or cards are moiftened with the pure alkalies, and particularly with a folution of pure ammonia, that the effect is much greater than by any other fubftance. This fact is, I believe, fufficient to prove that the oxydation of the metals is not the caufe of the phænomenon.

It is very convenient to ufe the alkalies in this manner, as it does not require fo much trouble to clean the metals, or to keep the pile in order.

I took ten faucers, and placed in each a plate of filver and 2 plate of zinc; I connected thefe metals in the feveral faucers together, by means of fips of tin-foil, and completed the circuit by means of wires in water. I firt filled thefe faucers with falt and water, and found that the wires in the water produced a trifling effect: fome few air-bubbles efcaped, which proved that the influence was excited. I then re- 